\title{
Oceanic eddies in synthetic aperture radar images
}

\author{
Andrei Yu IVAnOV* and AnNA I GinzBURG \\ P P Shirshov Institute of Oceanology, Russian Academy of Sciences, Nakhimovsky prospect, 36, Moscow, 117851, \\ Russia. \\ *e-mail: ivanoff@sio.rssi.ru
}

Continuous observations since 1991 by using synthetic aperture radar (SAR) on board the Almaz1, ERS-1/2, JERS-1, and RADARSAT satellites support the well-known fact that oceanic eddies are distributed worldwide in the ocean. The paper is devoted to an evaluation of the potential of SAR for detection of eddies and vortical motions in the ocean. The classification of typical vortical features in the ocean detected in remote sensing images (visible, infrared, and SAR) is presented as well as available information on their spatial and temporal scales. Examples of the Almaz-1 and ERS-1/2 SAR images showing different eddy types, such as rings, spiral eddies of the open ocean, eddies behind islands and in bays, spin-off eddies and mushroom-like structures (vortex dipoles) are given and discussed. It is shown that a common feature for most of the eddies detected in the SAR images is a broad spectrum of spatial scales, spiral shape and shear nature. It is concluded that the spaceborne SARs give valuable information on ocean eddies, especially in combination with visible and infrared satellite data.

\section{Introduction}

The study of oceanic eddies, which are essential elements of ocean dynamics, is very important because they determine horizontal mixing in the ocean (in particular, redistributing surface/subsurface pollution), influence marine biological population, etc. Monitoring of eddies generated due to barotropic-baroclinic instability of currents and fronts, interaction with bottom topography and atmospheric forcing (Fedorov 1986; Kamenkovich et al 1987; Eldevik and Dysthe 2000) can be carried out in two different ways. The first one is traditional contact measurements from research vessels, which are expensive and not operative and the second is satellite remote sensing methods. Results of the latter methods are not always easy to interpret. However, the most preferable way is to use both. Satellite infrared (IR) and visible sensors have served as remote sensing tools to study vortical mesoscale ocean dynamics for about 30 years. In particular, spi- ral eddies in the ocean were firstly detected in the pictures of sun glitter taken by astronauts during Apollo Missions in 1968 (Munk et al 2000). Photographs of eddies in coastal regions taken by astronaut Scully-Power during the Challenger mission in October 1984 have made a major contribution to oceanography (Scully-Power 1986).

The eddies' classification, firstly developed by Ginzburg (1992) on the basis of analysis of visible and infrared imagery, includes typical elements of nonstationary ocean dynamics, such as spiral eddies of the open ocean, eddies behind islands (island wakes), eddies due to the coastal geometry and bottom topography, mushroom-like currents and associated (attached) eddies. However, information gained in visible and IR bands essentially depends on illumination and cloud conditions and does not give such detailed structure of vortical motions in the ocean, as synthetic aperture radar (SAR) imagery does.

Keywords. Oceanic eddies; vortical motions; synthetic aperture radar (SAR); SAR images. 


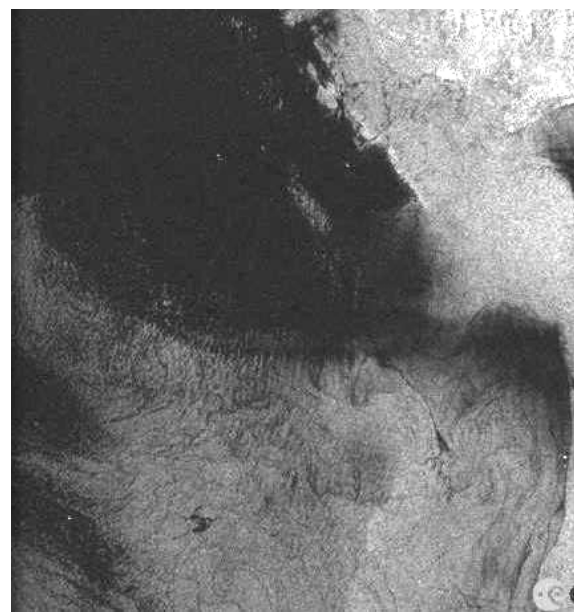

wind speed $0-3 \mathrm{~m} / \mathrm{s}$

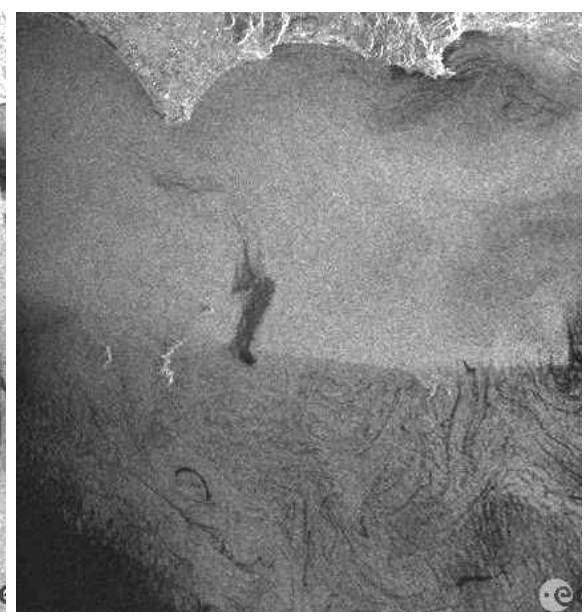

wind speed 3-5 m/s

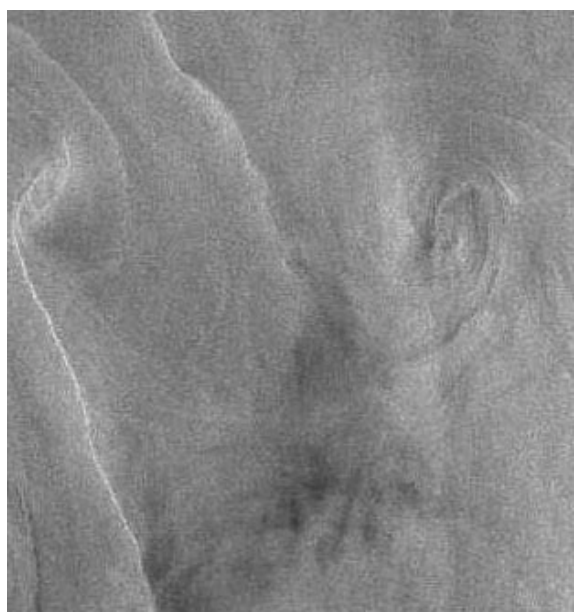

wind speed 6-7 m/s

Figure 1. At wind speeds between 3 and $5 \mathrm{~m} / \mathrm{s}$ eddy-like features or filaments are usually expressed through the presence of natural oil slicks, which are collected in convergence zones along spiral lines associated with the eddy orbital motion. The ERS-2 SAR images acquired in the Mediterranean Sea (September 12th, 2000) at wind speed 0-3 m/s (left) and 3-5 m/s (middle) demonstrate two boundary examples. At wind speeds about $6-7 \mathrm{~m} / \mathrm{s}$, eddies appear in the SAR imagery as a result of wave/current interaction which either outlines the shape of the eddy by bright (less often dark) linear features or displays only parts of these features. The ERS-2 SAR image acquired in the Kuroshio area on October 5th, 1998 (right) is an illustration of this process. CESA

Investigation of ocean dynamics with SAR began in the 1980s with the SEASAT SAR (Vesecky and Stewart 1982). Next generation of SAR on board the Almaz-1, ERS-1/2, JERS-1 and RADARSAT satellites has demonstrated a significant ability to image a number of ocean surface features associated with the upper ocean circulation and dynamics (Vesecky and Stewart 1982; Johannessen et al 1995; Johannessen et al 1996; Ivanov and Litovchenko 1998). These features also include ocean eddies and vortical motions and usually have a spiral form. It is important, therefore, to analyze the newly collected images of the last decade with the purpose of determining typical vortex motions in the ocean and their characteristics.

The satellite images of various oceanic eddies, both the above-mentioned nonstationary and quasi-stationary (long-lived) ring type were collected in P P Shirshov Institute of Oceanology RAS (IO RAS). Surface manifestations of these dynamic structures in the SAR imagery allow retrieval of the eddies' parameters, such as rotation direction, horizontal dimensions, spiraling order, eddy asymmetry and location of surface convergences (an example of determination of velocity and sense of rotation of ocean gyres with the SAR imagery was considered by Vyas and Andharia 1987). The objectives of this paper are to classify eddies visible in the SAR images, to determine their spatial scales, and to clarify, wherever possible, the generation mechanisms and relation between eddies and their manifestations at the sea surface.

\section{Ocean eddies in the SAR images}

\subsection{Environmental conditions for eddy detection}

Eddies usually appear in the SAR images indirectly, due to the presence of natural films trapped within spiral lines associated with eddy orbital motion, which leads to backscatter contrasts up to 5-10 dB (Alpers and Huhnerfuss 1989), or as a result of wave/current interaction (Johannessen et al 1995; Johannessen et al 1991) that outlines the shape of an eddy. Analysis of the SAR imagery has shown that visibility of eddies strongly depends on wind speed. Under wind speeds between 3 and $5-7 \mathrm{~m} / \mathrm{s}$, oceanic eddies are often marked by natural oil slicks accumulated in convergence zones (Johannessen et al 1995). In this case eddies look like classic spiral structures. Spiral lines are suggested to be associated with convergences towards the eddy center (Johannessen et al 1995; Johannessen et al 1996). The spacing between spiral lines is of the order of several $\mathrm{km}$ (typically $1-5 \mathrm{~km}$ ).

The ERS-2 SAR images in figure 1 (left and middle) acquired in the Mediterranean Sea demonstrate two boundary examples when eddy-like features or filaments are marked by oil slicks. Surface manifestations of an eddy in the Kuroshio area, which appear in the SAR image as a result of wave/current interaction, are not easy to interpret (figure 1, right). The ERS-2 SAR images acquired in the Black Sea (figure 2, left) and Japan Sea (figure 2, right) demonstrate a typical 

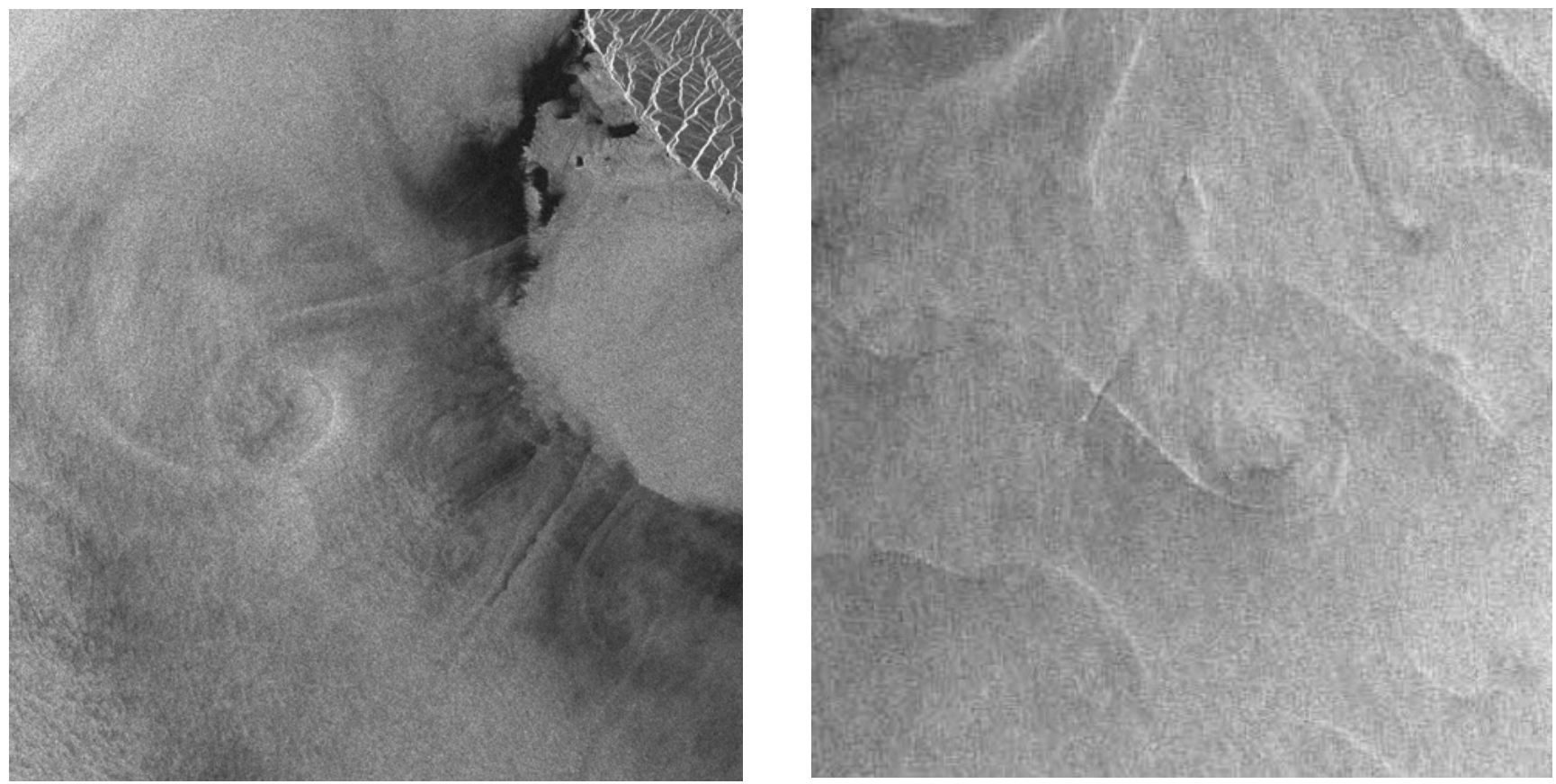

Figure 2. Eddies, which appear in the SAR images as a result of wave/current interaction, are not easy to interpret. These ERS-2 SAR images acquired in the Black Sea on April 10th, 1994 (left) and Japan Sea on December 23rd, 1994 (right) show a typical problem of SAR image interpretation: a case of easy interpretation is shown on the left; more complicated case is on the right (size of the eddies is about $5-7 \mathrm{~km}$ ). (CESA

problem of the SAR image interpretation: a case of valid interpretation is shown on the left; a more complicated case is on the right (size of the eddies is about $5-7 \mathrm{~km}$ ). Dark spiral lines are expected to disappear at higher wind speed due to wind-induced mixing of the upper layer and redistribution of surface films (Scott 1986). Actually, under wind speed of $6-7 \mathrm{~m} / \mathrm{s}$ eddy signatures usually change their appearance from dark to bright, with only fragmentary marks in the eddy structure that apparently do not spatially coincide with dark spiral lines (figure 1, right; figure 2, right). Bright (less often dark) linear/arc features either outline the shape of an eddy or display only parts of the eddy structure that depend on the viewing geometry, feature heading, wind and wave direction (figure 1, right; figure 2) (Lyzenga, 1991). This fact demonstrates different mechanisms responsible for imaging ocean vortical features in the SAR imagery. In the first case, the effect is made evident by oil film accumulation in convergence zones associated with eddy vortical motion, while in the second one it is due to wind/wave interaction with the current boundaries (current shears). The corresponding imaging mechanism alternates between the following (Grodsky et al 2000):

- short gravity wave/current interaction along shear and/or convergence zones within the eddy, and

- medium wave/current interaction.

\subsection{Types of oceanic eddies in the SAR images}

Following the purposes of the paper, we will demonstrate a manifestation of various oceanic eddies in the SAR imagery. A summary information on both long-lived eddies (rings) and nonstationary ones, as well as on their spatial and temporal characteristics (wherever possible), direction of rotation $(\mathrm{C}$-cyclonic, $\mathrm{A}$ - anticyclonic; the most typical is underlined) and characteristic patterns inferred from analysis of satellite images and sparse available field measurements is given in table 1 . The scales of eddies in table 1 are a summary of many case observations and studies conducted in IO RAS in 1980-1990 on a basis of IR and visible imagery analysis (Ginzburg 1992). The brief characterization of the eddies and relevant examples of the SAR images are presented as follows.

Spiral eddies of the open ocean, mostly cyclonic, with diameters less than $30 \mathrm{~km}$, are widespread in the ocean beyond $6^{\circ} \mathrm{N}-6^{\circ} \mathrm{S}$, including the areas where there is no shear flow or it is weak. Numerous examples of such eddies can be found in Oceanography from Space Shuttle (1989) and Munk et al (2000). Unfortunately, we did not find similar examples of solitary spiral eddies in the collected SAR imagery. Nevertheless, closely spaced cyclonic spiral eddies may be seen in figures 3 and 4 . 
Table 1. Types of eddies (vortex motion) in the ocean (C-cyclonic; $A$-anticyclonic); the most typical type of rotation is underlined.

\begin{tabular}{|c|c|c|c|c|c|c|}
\hline & Type & $\begin{array}{l}\text { Horizontal } \\
\text { scale }(\mathrm{km})\end{array}$ & $\begin{array}{l}\text { Vertical } \\
\text { scale }(\mathrm{m})\end{array}$ & $\begin{array}{l}\text { Lifetime } \\
\text { (days) }\end{array}$ & $\begin{array}{l}\text { Direction } \\
\text { of rotation }\end{array}$ & Surface pattern \\
\hline 1 & $\begin{array}{l}\text { Spiral eddies of the open } \\
\text { ocean }\end{array}$ & $1-30$ & up to 300 & $?$ & $\underline{\mathrm{C}}, \mathrm{A}$ & 6 \\
\hline 2 & $\begin{array}{l}\text { Eddies behind the islands: } \\
\text { standing eddies } \\
\text { vortex streets }\end{array}$ & $0.1-5$ & $1-?$ & $<0.5-?$ & $\mathrm{C}, \mathrm{A}$ & बहलंखें \\
\hline \multirow[t]{3}{*}{3} & $\begin{array}{l}\text { Eddies due to inhomo- } \\
\text { geneity of a shoreline: }\end{array}$ & & & & & \\
\hline & Near capes & $1-100$ & $10-?$ & $0.5-?$ & $\begin{array}{l}\mathrm{C}, \mathrm{A}, \\
\text { dipole }\end{array}$ & \\
\hline & In the bays & & & & & \\
\hline 4 & Chains of shear eddies & $0.02-100$ & $10-100$ & $3 ?$ & $\underline{\mathrm{C}}, \mathrm{A}$ & SSGप \\
\hline 5 & $\begin{array}{l}\text { Eddies in areas of flow } \\
\text { confluence (separation) }\end{array}$ & $0.1-300$ & $?$ & $20 ?$ & $\mathrm{C}, \mathrm{A}$ & $y^{6}$ \\
\hline 6 & Spin-off eddies & $25-60$ & $<100$ & $<10$ & $\underline{\mathrm{C}}, \mathrm{A}$ & \\
\hline 7 & Warm/cold core rings & $90-300$ & $300-1000$ & $30-400$ & $\mathrm{C}, \mathrm{A}$ & \\
\hline 8 & Associated eddies & $20-100$ & $20-100$ & $1-30$ & $\underline{\mathrm{C}}, \mathrm{A}$ & \\
\hline 9 & $\begin{array}{l}\text { Mushroom-like currents } \\
\text { (patterns) }\end{array}$ & $1-200$ & $10-100$ & $1-30$ & dipole & $\%$ \\
\hline
\end{tabular}

Eddies behind islands (island wakes) are associated with instability of shear layers that are formed on both sides of an island when a stream flows around it. The structure of the current varies qualitatively just as behind a circular cylinder in laboratory experiments, depending on flow velocity $(U)$ and island cross section. For example, in the case of an island size of about $5 \mathrm{~km}$, Pattiaratchi et al (1987) observed the absence of eddies at $U=0.25 \mathrm{~m} / \mathrm{s}$, a pair of standing eddies at $U=0.5-0.6 \mathrm{~m} / \mathrm{s}$, and von Karman vortex street at $U>0.6 \mathrm{~m} / \mathrm{s}$. Figure 5 shows surface manifestations of nonstationary vortical motions behind Isl. Diomid and a series of von Karman vortex streets behind Fairway Rock in the Bering Strait on the ERS-1/2 SAR images acquired on different days. The scales of vortexes in the street are commensurable to dimensions of the rock (of the order of $1 \mathrm{~km}$ ). The vortex street can be seen over a distance of about $10 \mathrm{~km}$ (several wavelengths $\lambda$, see sketch in table 1). It follows from figure 5 that the parameter $m / \lambda$ ( $m$ is the distance between centers of eddy pairs, see table 1 ) evidently exceeds 0.28 , which is the criterion of von Karman street stability (Pattiaratchi et al 1987). Variability of the vortical pattern behind Fairway Rock in figure 5 is most likely determined by the variability of the northward current velocity (Lavrova and Sabinin 2000).
Eddies due to inhomogeneity of the shoreline originate near capes and as a result of local circulation in the bays or channels. They may be related to the resulting shear flow instability. Dimensions of these vortexes are determined by sizes of the bays or capes as well as by both intensity and duration of the current. An enlarged fragment of the Almaz-1 SAR image showing a ship crossing the eddy in the Bay Tongue of the Ocean (the Bahamas) is presented in figure 6. A character of displacement of the track suggests a cyclonic rotation of the eddy (Ivanov 1999) and at known vessel speed allows us to define rotation velocity of eddy. A typical example of an eddy at a cape off Sicily is seen on the ERS-2 SAR image (figure 7).

Frontal or spin-off eddies represent asymmetrical spiral structures and frequently are suggestive of jets pointed away from the basic current; they are always cyclonic. A spin-off eddy on the ERS-1 SAR image in the Norwegian Sea visualized by oil slicks is shown in figure 8 . Note that the spacing between spiraling lines is of the order of several $\mathrm{km}$ (typically $1-3 \mathrm{~km}$ ).

Chains of shear eddies are horizontal versions of the Kelvin-Helmholtz instability. These eddies differ from frontal (spin-off) cyclonic eddies: they have marked spiral form, ratio between their transversal and longitudinal scales ( $L$ and $\lambda$ in 


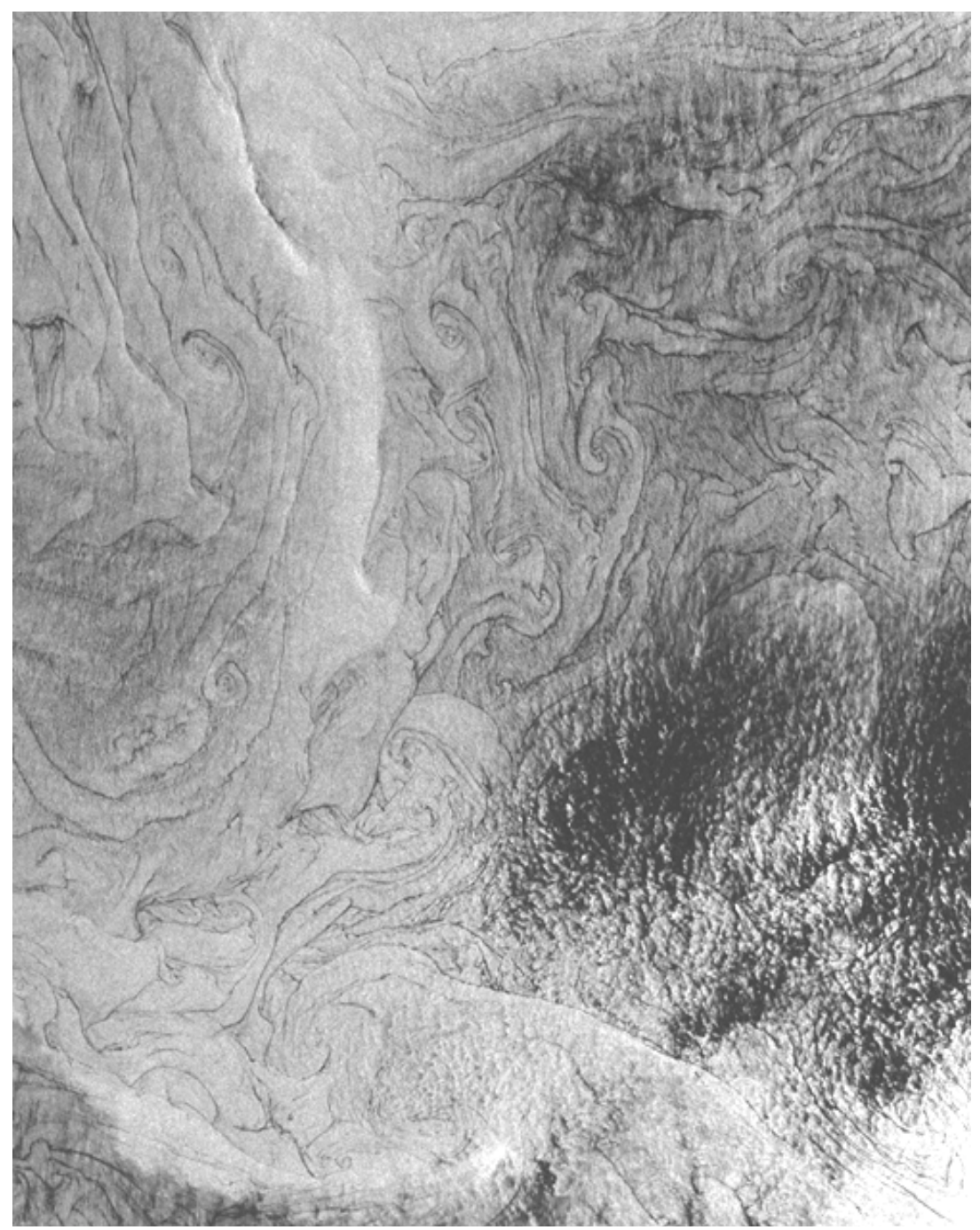

Figure 3. Chains of small-scale cyclonic eddies (size $3-5 \mathrm{~km}$ ) in the Japan Sea on the ERS-1 SAR image of October 22 nd, 1992. CESA

table 1 , respectively) is close to 1 in accordance with shear instability theory (Brown 1980), and they can be both cyclonic and anticyclonic. Apparently chains of such eddies grow due to barotropic instability in the shear areas that is also the cause in case of frontal eddies. The number of eddies in a chain varies from 2 to 6 , and the ratio of an eddy diameter to a wavelength of the chain varies from 0.25 to 0.7 . The chains of shear eddies were observed in various regions of the ocean: when the currents separate from the shelf or shore, in the cases of sharp change of the shoreline configuration, at fronts, and in areas of local current shear, etc. A chain of cyclonic eddies in the Mediterranean Sea on the ERS-2 SAR image near Cyprus (image size $40 \times 40 \mathrm{~km}$ ) is shown in figure 9.

Eddies in area of confluence/separation of currents arise as a result of interaction of two differently directed flows. Various types of flow inter- action are possible: for example, merging of river outflows, interaction of a flow from the strait with a quasi-stationary current or of two currents. The determining mechanism of eddy formation in this case is the vorticity (shear) of the currents or deviation of one current by another. Figure 10 shows the ERS-1 SAR image with a couple of cyclonic eddies that is supposedly located in the area of confluence of oppositely directed currents in the central part of the Japan Sea. Eddies became visible due to natural oil films and man-made surfactants; the source was two oil patches just below the eddy.

Warm/cold core rings (or mesoscale eddies) are related to meandering of the main geostrophic currents (Kamenkovich et al 1987). Rings usually range in diameter from 100 to $300 \mathrm{~km}$; their surface current velocity is about $1-1.5 \mathrm{~m} / \mathrm{s}$, and temperature contrast relative to the surrounding water reaches $2-3^{\circ} \mathrm{C}$ at the sea surface and up 


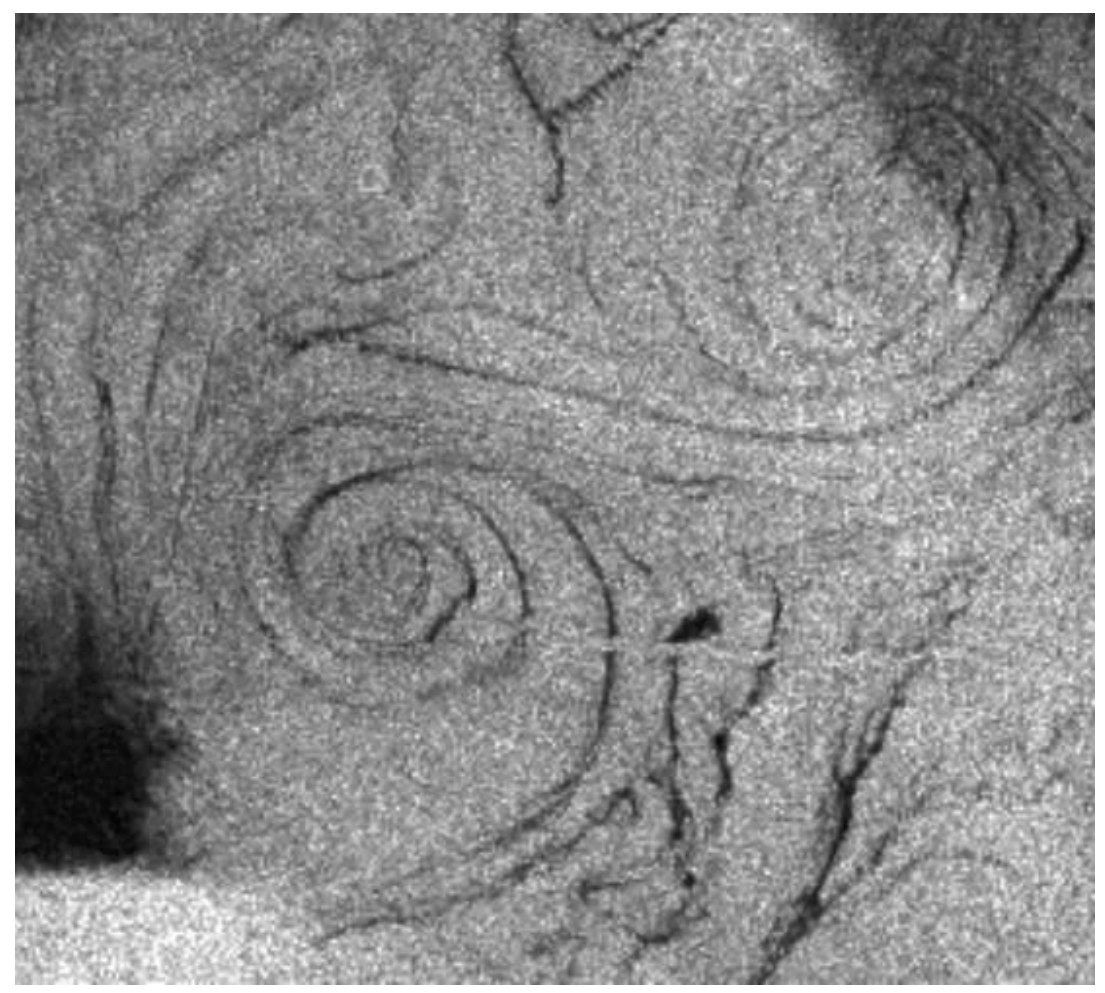

Figure 4. ERS-2 SAR image (September 19th, 1993) of two cyclonic eddies off Sicily in the Mediterranean Sea (image size $15 \times 13 \mathrm{~km})$. CESA
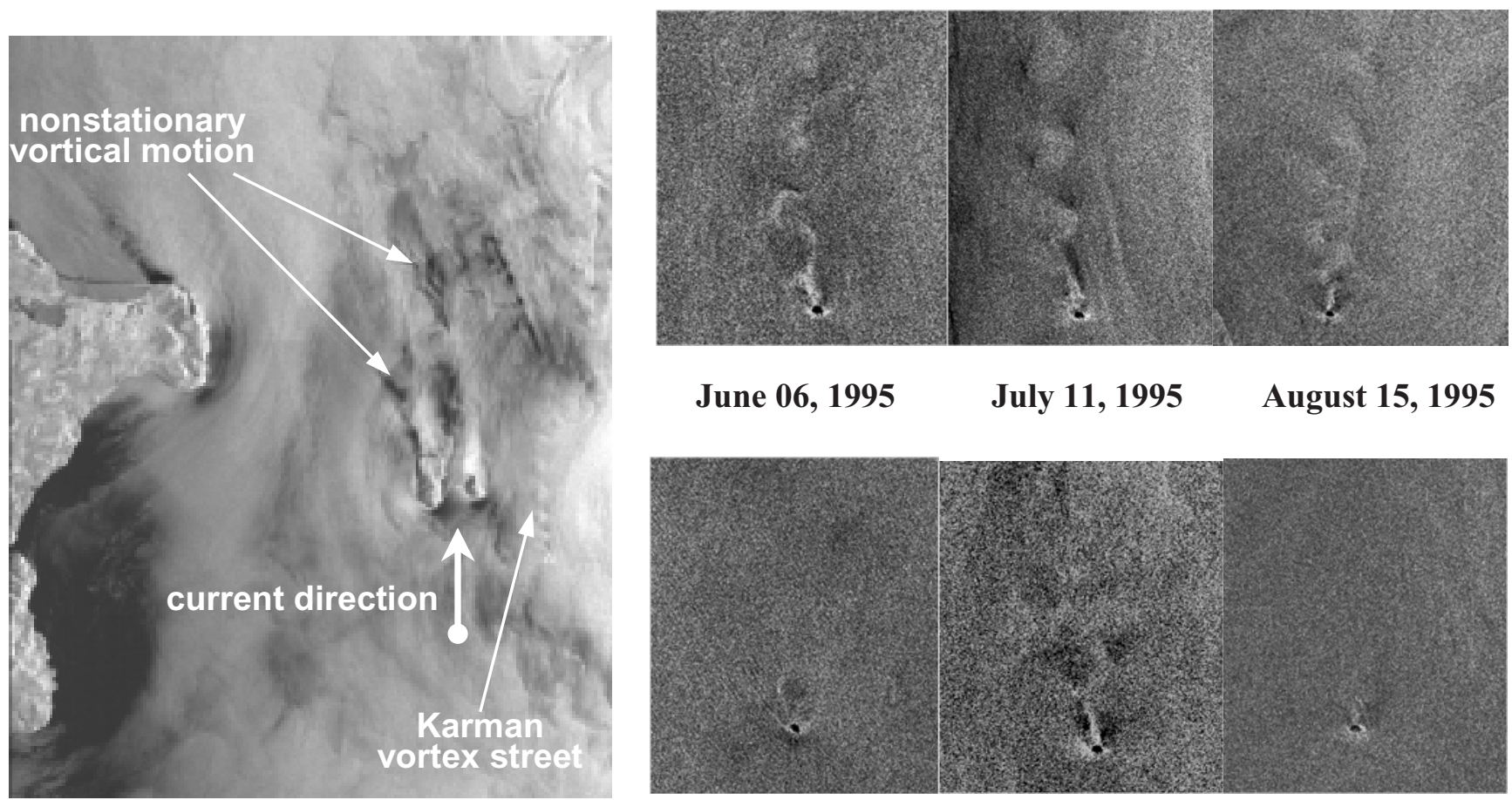

June 06, 1995

July 11, 1995

August 15, 1995

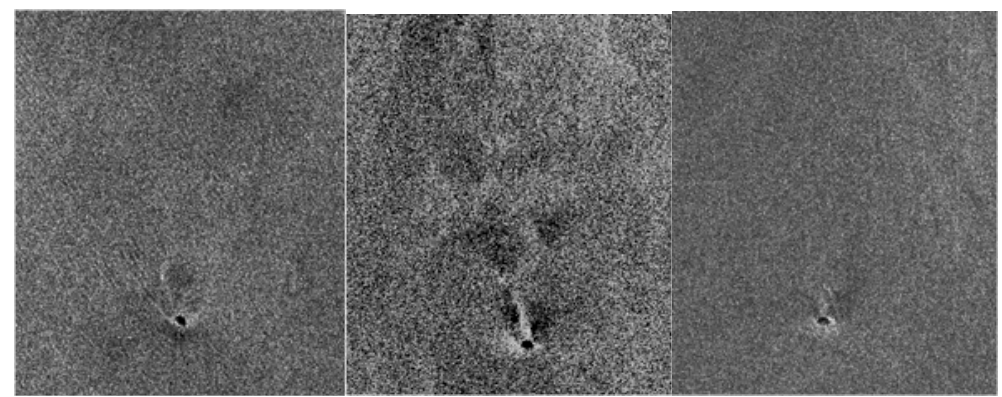

\section{August 31, $1995 \quad$ July 01, 1998}

August 02, 1998

Figure 5. Nonstationary vortex motion behind Isl. Diomid and von Karman vortex street behind Fairway Rock in the Bering Strait on the ERS-1 SAR image of July 11th 1995 (left). Surface manifestations of the vortex streets behind Fairway Rock in the Bering Strait on the ERS-1/2 SAR images (right). The manifestations strongly depend on the current direction as well as current velocity value. CESA 


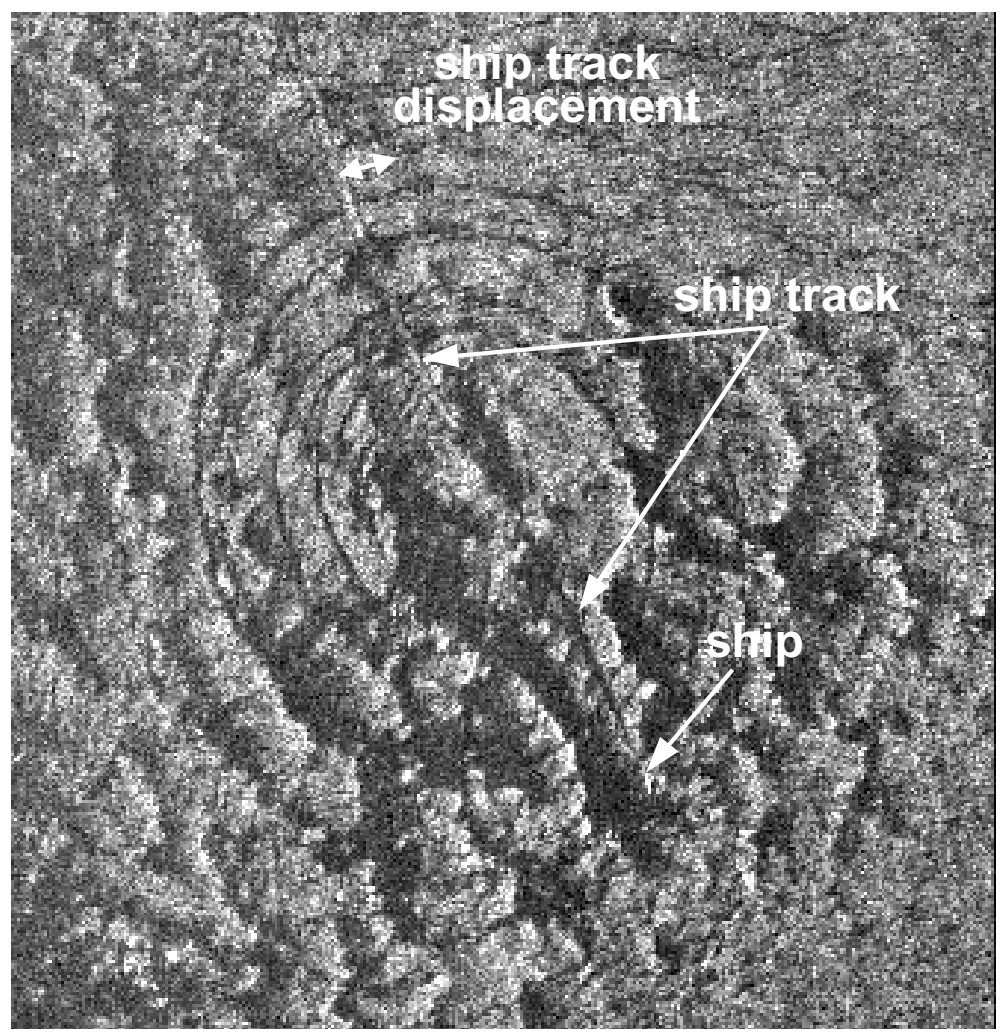

Figure 6. Enlarged fragment of the Almaz-1 SAR image of October 7th, $1992(25 \times 25 \mathrm{~km})$ showing a ship crossing the eddy located in the Bay Tongue of the Ocean (the Bahamas). (CNPO Mashinostroenia

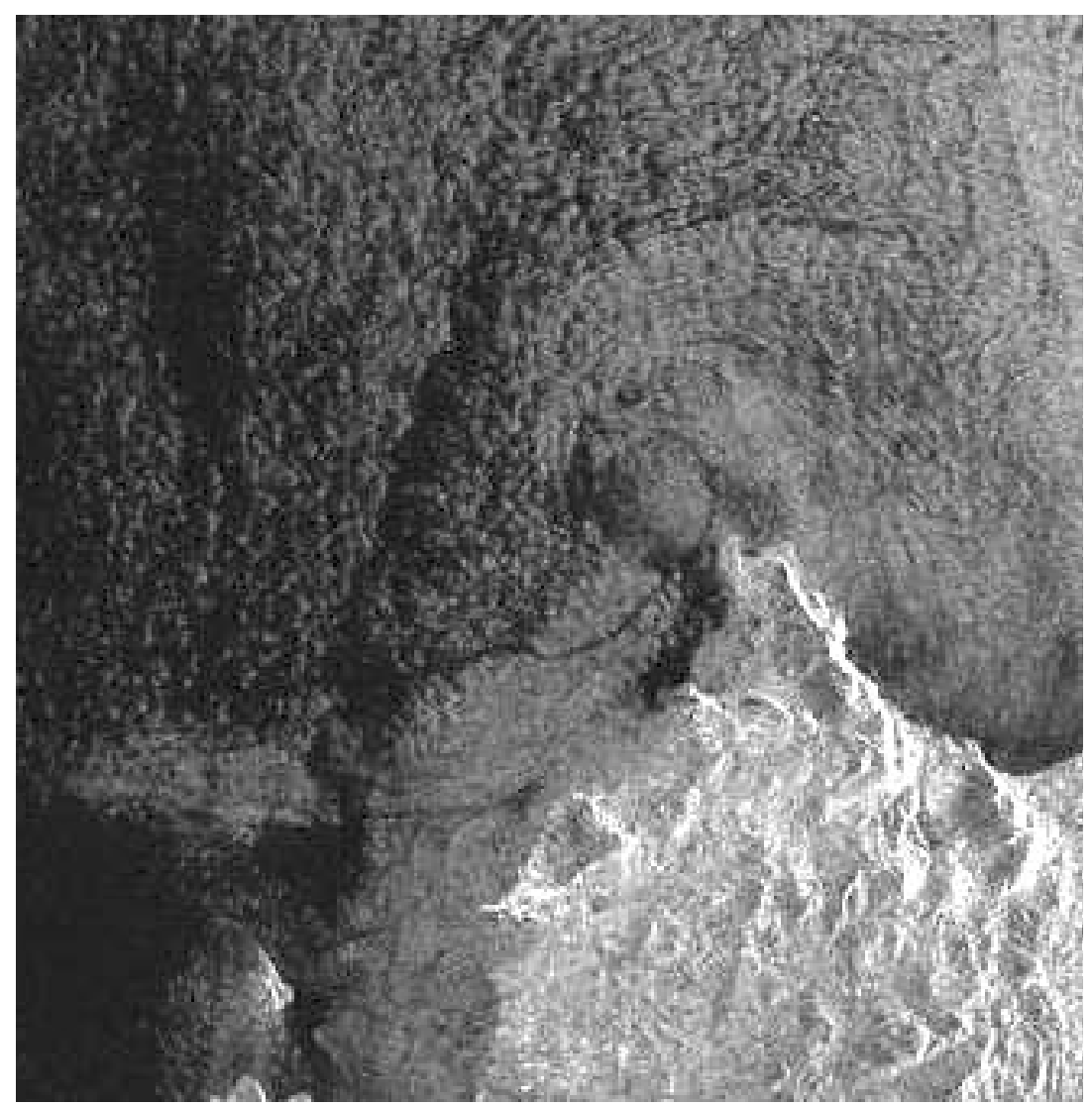

Figure 7. Eddy at a cape off Sicily on the ERS-2 SAR image of September 12th 2000. CESA 


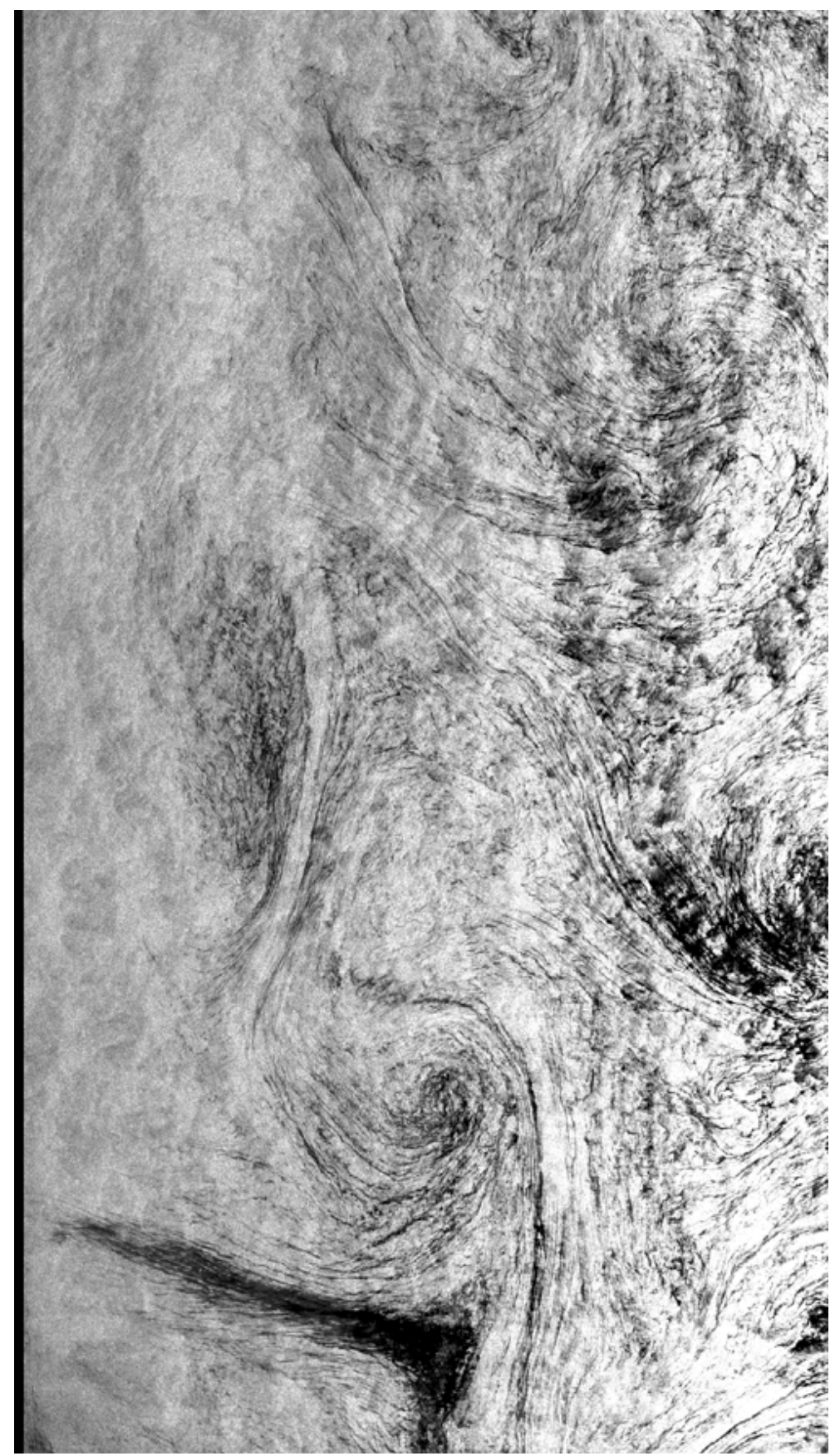

Figure 8. Spin-off eddies in the Norwegian Sea on the ERS-1 SAR image of July 7th 1997 visualized by oil slicks (image size $100 \times 200 \mathrm{~km})$. CESA

to $10^{\circ} \mathrm{C}$ at a depth of $300-400 \mathrm{~m}$. Most remarkable features of the SAR images of warm/cold core rings is the so-called "mottled" texture of the inside of the eddy (firstly detected in the SEASAT SAR images of the Gulf Stream warm core rings) and linear/arc features (fronts) (Lichy et al 1981) that are visible due to wave/current interaction and mark the eddy boundaries, bright or dark, depending on the viewing geometry, direction of the features, wind and wave direction (Lyzenga 1991; Grodsky et al 2000). This is a result of the wind direction dependency of the capillaries and short gravity waves that are seen by the SAR. Analysis of the available SAR images of rings with diameter more than $150 \mathrm{~km}$ has shown that surface manifestations of the rings, both warm and cold, are usually (but not always) brighter than that of the surrounding waters. Apart from a mechanism related to a difference in atmosphere boundary layer stratification due to air-sea temperature differences, there are two others (waves/current and short/long waves 


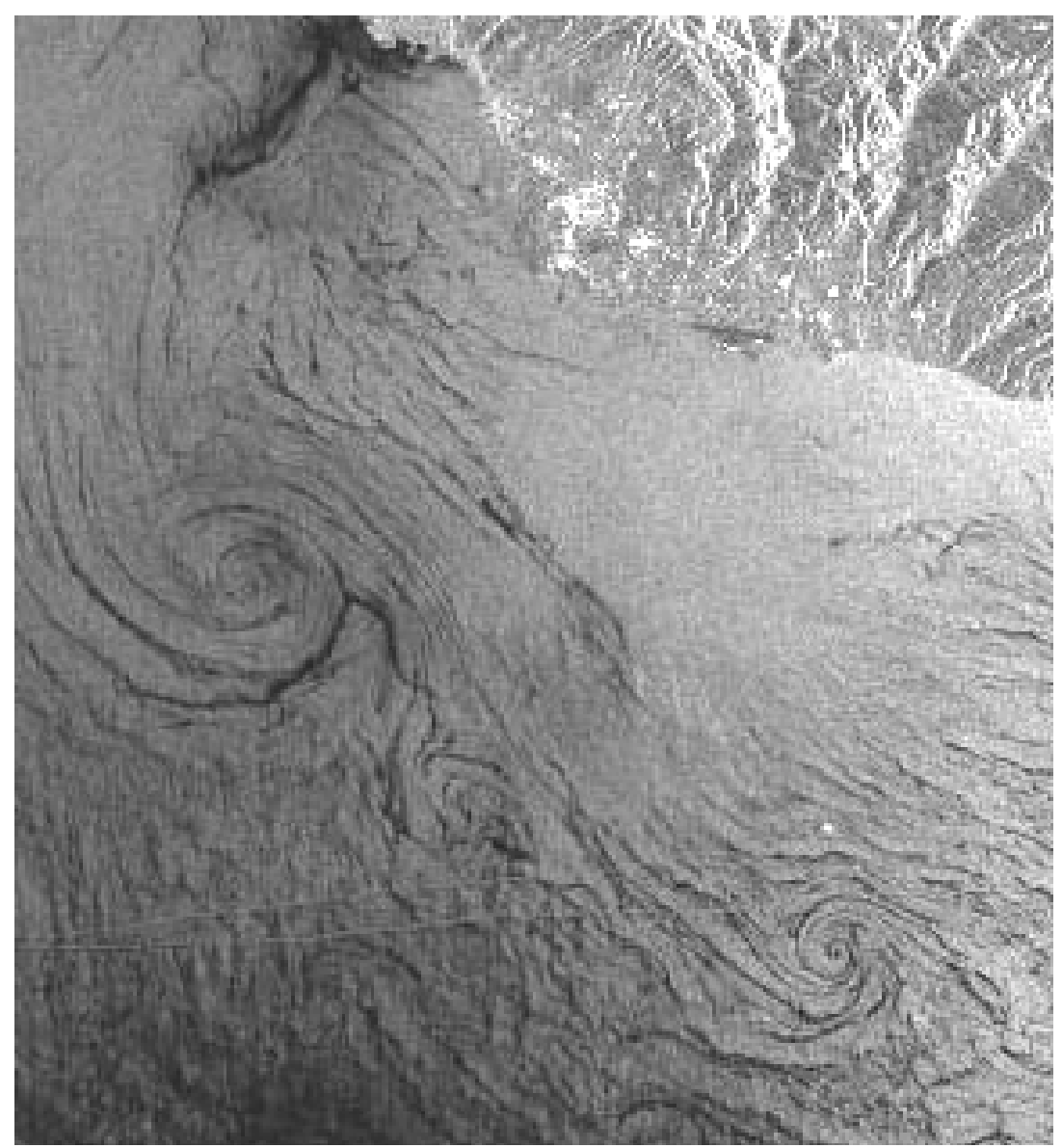

Figure 9. A chain of cyclonic eddies in the Mediterranean Sea image near Cyprus on the ERS-2 SAR of October 10th $1994(40 \times 40 \mathrm{~km})$. CESA

interactions) that significantly contribute to SAR image formation of oceanic rings. In general these two last mechanisms produce characteristic mottled texture of rings on the SAR images that results in an increase of image brightness. The reader can find some additional evidences on this subject in Cheney (1981), Fu and Holt (1982) and Grodsky et al (2000). Subscene of the high resolution Almaz-1 SAR image in figure 11 shows the boundary of a young warm core ring of the Gulf Stream under wind speed of $12-13 \mathrm{~m} / \mathrm{s}$. The most remarkable features of this image are mottled texture of the ring and its rough boundary of variable contrast.

Associated (attached) eddies are formed when rings (eddies) interact with fronts or as a result of their own evolution. Analysis of satellite imagery has shown that the essential property of mesoscale eddies is the formation of dipole or multipole structures from maternal eddy (anticyclonic in most cases) and one or several associated eddies of opposite sign at its periphery. Sketch in figure 12 shows the formation of two associated eddies at the periphery of a large anticyclonic eddy (ring) (Ginzburg 1992). Unfortu- nately, we couldn't find the SAR images of such structures.

The mushroom-like patterns (combination of vortex dipoles with jet flows between cyclonic and anticyclonic counterparts) are the universal response of the upper layer of the ocean to various localized impulse-type forcing and the way of its returning to the quasi-stationary state (Fedorov and Ginsburg 1986, 1992). Horizontal scale of the structures is approximately equal to the size of a vortex dipole and ranges from several $\mathrm{km}$ (for example, when a structure is a result of outflow from the channel) to about $200 \mathrm{~km}$ (when a structure is a combination of a large-scale and relatively long-lived eddy with a rather short-lived associated one). Dipoles can be quasi-symmetric or asymmetric, with asymmetry of both signs (anticyclonic or cyclonic, the first one being the most typical). Vertical scales of dipole counterparts depend on the mechanism of their formation and may be both the same (in the case of outflow from the channel, when both eddies are formed in the surface layer) and considerably different (the case of a dipole from a ring and shallower associated eddy). Properties of 


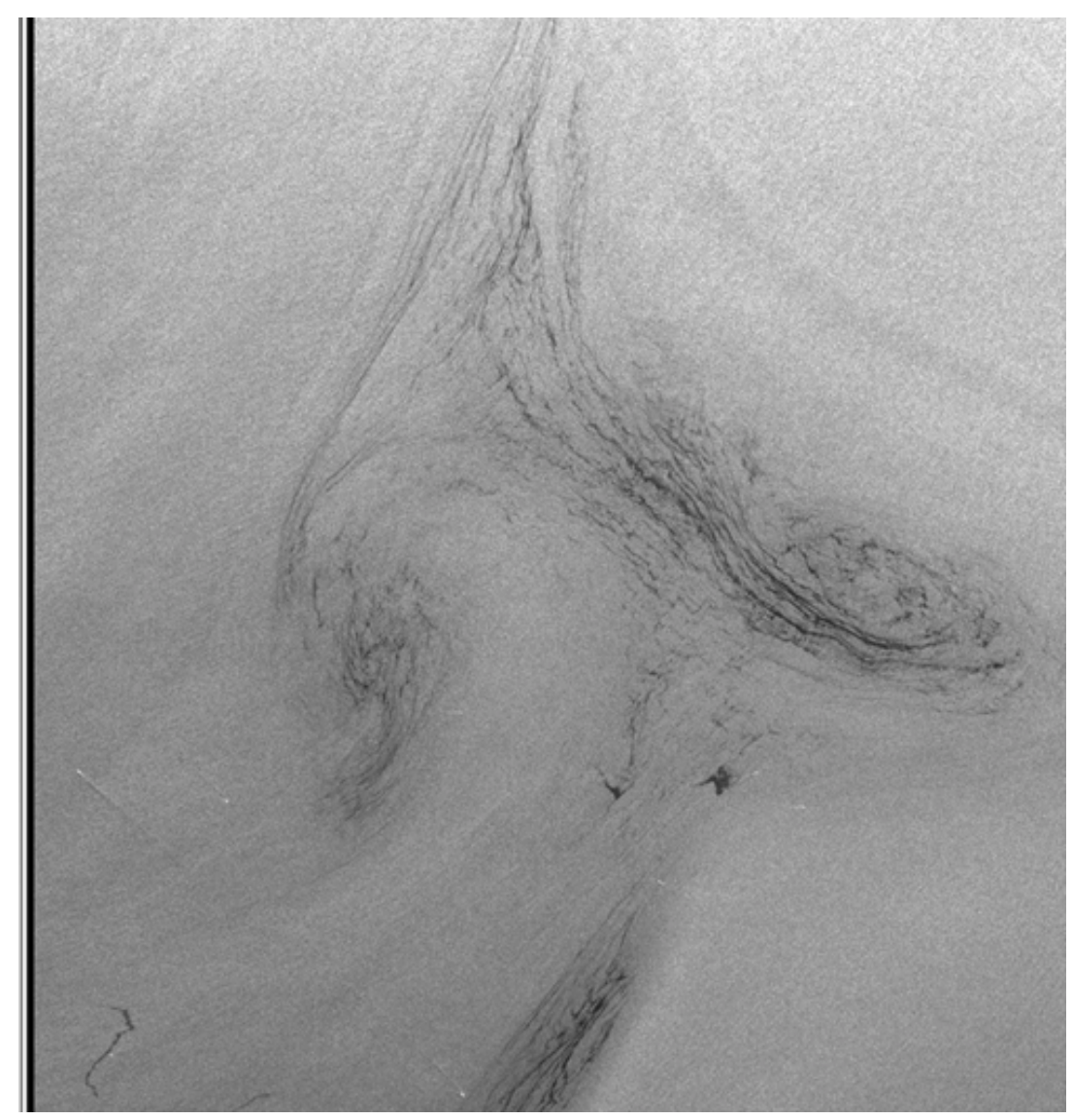

Figure 10. Two cyclonic eddies in the area of confluence of oppositely directed currents in the Japan Sea (ERS-1 SAR image of April 27th, 1994, $80 \times 80 \mathrm{~km})$. CESA

mushroom-like currents forming composite multipolar structures (packing of mushroom-like structures) make these currents the effective mechanism of horizontal mixing in the ocean. Figure 13 shows mushroom-like patterns in the Caspian Sea to the south of the Volga River estuary on the ERS-2 SAR image.

\section{A multi-sensor approach}

The interpretation of the SAR imagery often becomes difficult due to the fact that the observed field of short wave intensity (radar cross section) depends on a number of phenomena which arise at the ocean/atmosphere interface. An operational measuring and monitoring of the phenomena associated with oceanic vortical motions requires appropriate spaceborne techniques and ground truth measurements. Manifestations of these phenomena are usually determined by small-scale variations of surface waves and currents as well as by distributions of chlorophyll $a$, surface temperature, oil slicks and floating ice (ice floes at the sea surface are a good tracer of the ocean circulation in the polar regions). Eddies of different origin in the marginal ice zone can be traced and monitored by SAR in a broad range of environmental conditions (Johannessen et al 1987).

Therefore data from different satellites and sensors can be used to characterize mesoscale and sub-mesoscale oceanic eddies. They include sea surface temperature from NOAA AVHRR or ERS ATSR, chlorophyll concentration from SeaWiFS, OCM or CZCS sensors, SAR images from ERS2 or RADARSAT, as well as sea level data from the TOPEX/Poseidon or ERS-1/2 altimeter. Combining data from these satellites can give a good opportunity to better understand eddy dynamics, their origin, evolution and decay. Synergic use of data from SAR, optical and IR sensors can increase our ability to detect, classify and interpret vortex patterns in the ocean. The ASAR and MERIS instruments on board the recently launched ENVISAT satellite offer such an opportunity. The examples of joint use of different sensors for identification of the vortical oceanic features are given in figures 14 and 15. Figure 14 is reproduced from Lobanov et al (2000) showing an anticyclonic eddy in the Sea of Okhotsk 


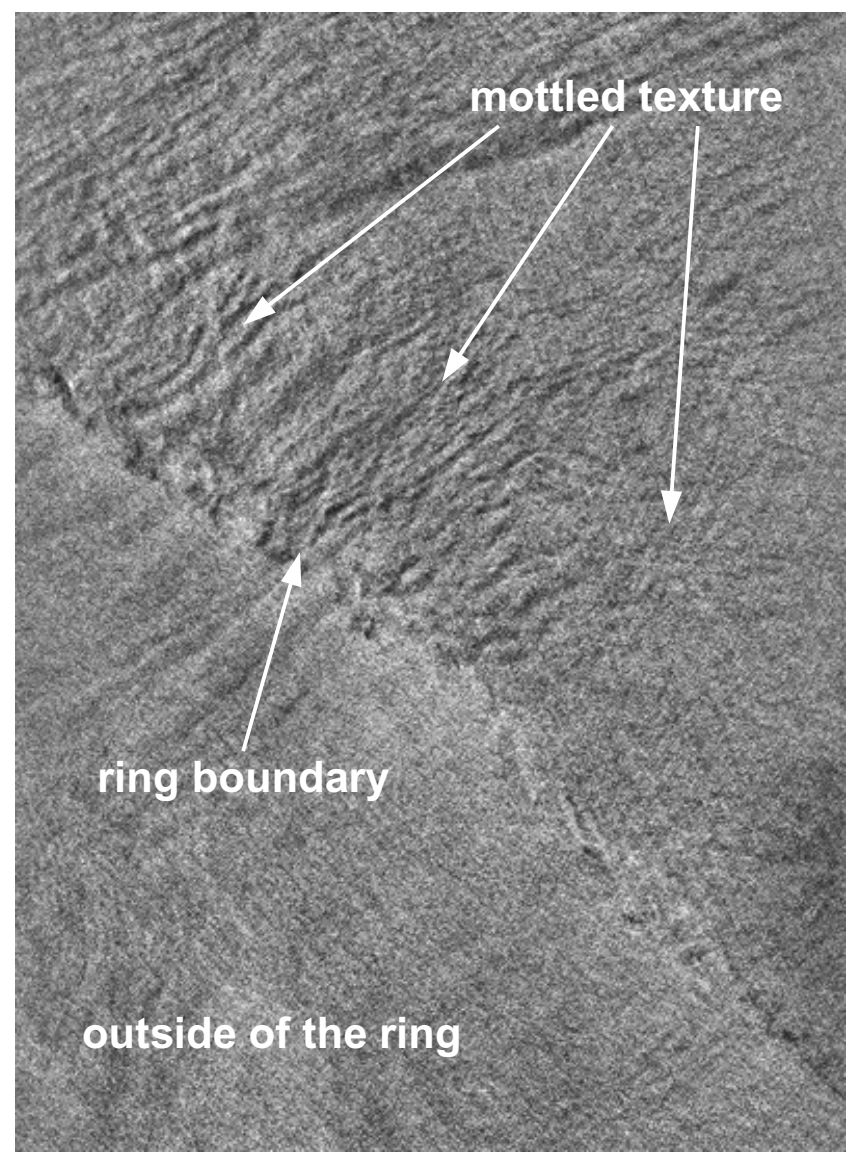

Figure 11. Subscene of the high resolution Almaz-1 SAR image of September 7th, $1992(50 \times 70 \mathrm{~km})$ showing boundary of young warm core ring of the Gulf Stream at wind speed $12-13 \mathrm{~m} / \mathrm{s}$. Most remarkable features of this image are mottled texture of the ring and rough ring boundary of variable contrast. (CNPO Mashinostroenia

in the ERS-1 SAR image for April 22nd, 1995 (left) and in the NOAA AVHRR image for April 25th, 1995 (right). Melting ice is a tracer in this case. Shear cyclonic elements at the southern and eastern parts of the eddy periphery are well seen in both images. In a time of 3 days between the images the eddy shape and spatial orientation were not changed, however displacement of shear elements at its periphery in the direction of eddy rotation (anticyclonic) was evident. Figure 15 reproduced from Stapleton et al (2000) shows an eddy structure (presumably, a dipole) traced by phytoplankton concentration in the SeaWiFS image (left) and by surface films in the SAR image (right) in the Gulf of Oman on March 8th, 1999. Both components of the dipole may be seen in the SeaWiFS image, whereas in the SAR image only the cyclonic eddy is clearly seen. On the other hand, alongshore slicks revealed in the latter image are not seen in the former one. The reader can find more discussion and detail interpretation of the images presented in figures 14 and 15

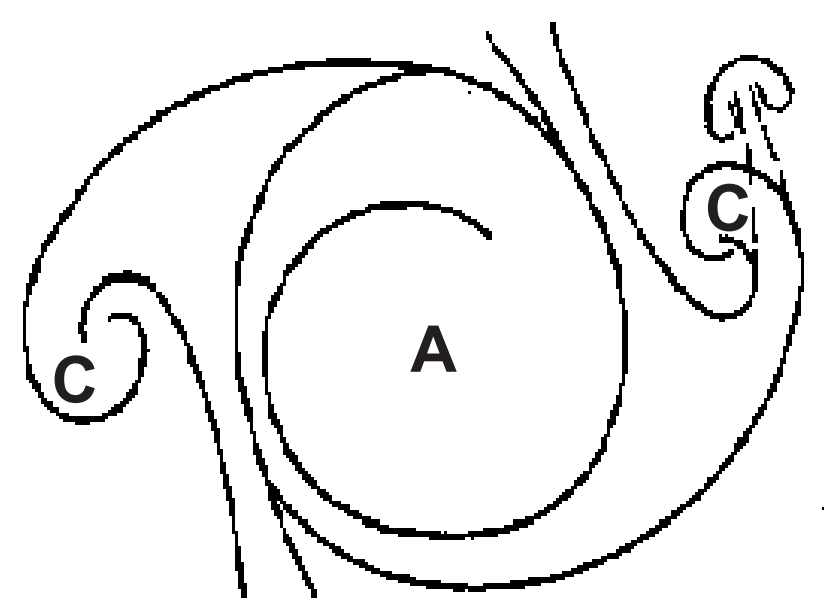

Figure 12. The sketch showing formation of two attached cyclonic (C) eddies at the periphery of a large anticyclonic (A) eddy (ring).

in Lobanov et al (2000) and Stapleton et al (2000), respectively.

Satellite altimeters and altimeter data can also be used for these purposes. As seen from recent papers by Mayers and Basu (1999) and Gairola et al (2001) they are a valuable source of additional information allowing both detection and measurements of a number of eddy parameters.

\section{Conclusions}

There is a broad spectrum of space-time scales of vortical motions in the ocean. The basic mechanism of generation of the considered nonstationary eddies in the ocean is most likely a shear flow instability. The majority of oceanic eddies have characteristic surface manifestations that allow them to be classified using the surface signatures. Most eddy types can be detected with spaceborne SARs. Environmental conditions for eddy observation with SAR are narrow, and common for wind speeds from 3 to $7 \mathrm{~m} / \mathrm{s}$. An SAR can image eddies of different spatial scales (from 1 to $200 \mathrm{~km}$ ) as spirals or series of bright (rarely dark) arc/linear features. As distinct from sensors in infrared and visible bands, radar is an all-weather instrument. By analyzing the SAR imagery characteristics of eddies such as rotational direction, horizontal dimensions, spiraling order, eddy asymmetry, etc. can be extracted. Consequently, the progress in investigation of oceanic eddies will be enhanced with accumulation of the SAR images displaying eddy dynamics and evolution. 


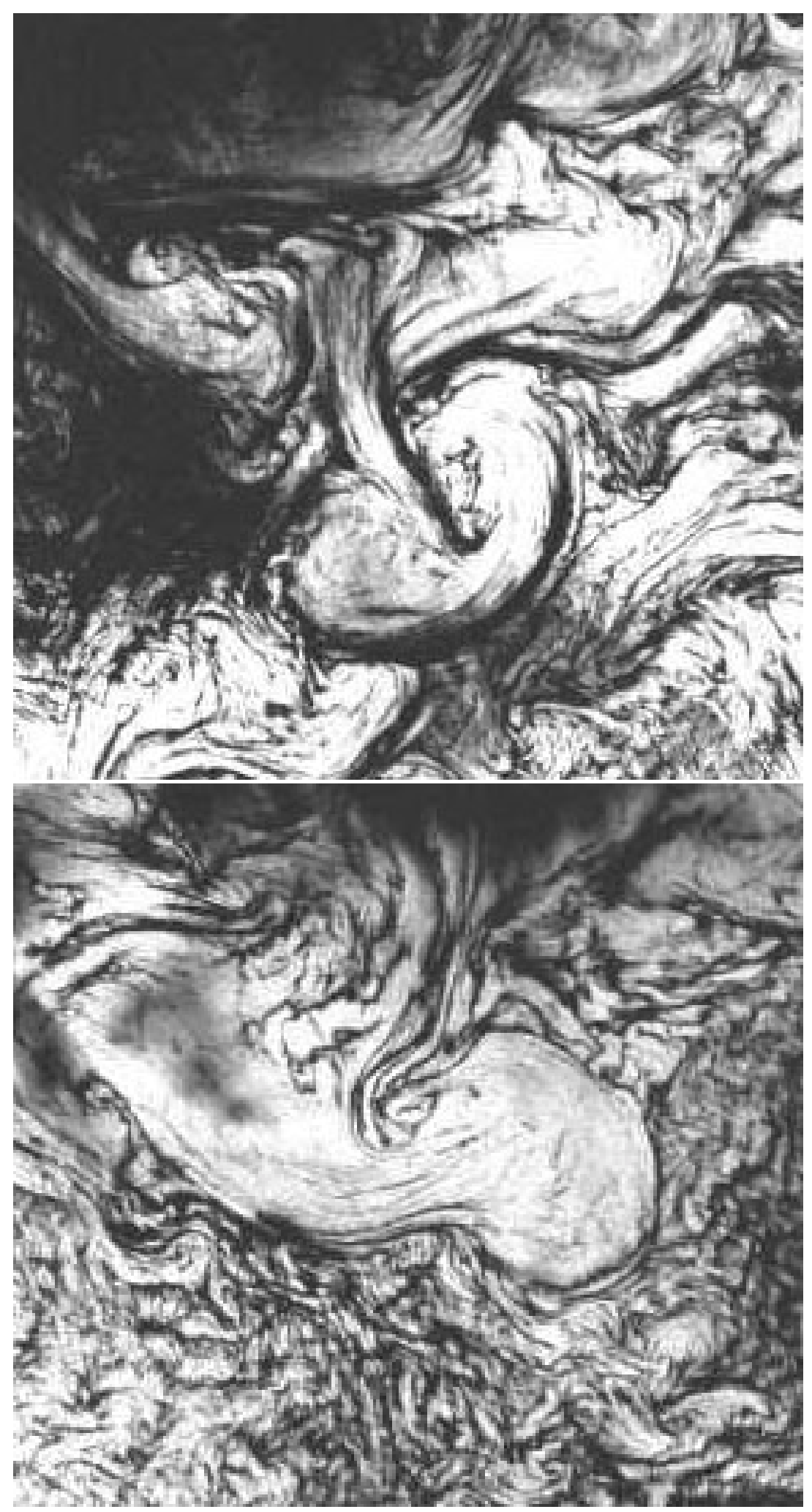

Figure 13. Mushroom-like patterns in the Caspian Sea to the south off the Volga estuary consisting of two counter-rotating eddies, cyclone and anticyclone, on the ERS-1 SAR image of October 12th 1993. One of them is fully developed (up), while another one is in a developing phase (bottom) (for more detail description see at http://www.ifm.uni-hamburg.de/ers-sar). (C)ESA

On the one hand, the results support the idea that SAR techniques form a valuable tool for observation of ocean dynamics features because the
SAR has high spatial resolution and is practically a weather independent instrument. On the other hand, the present-day spaceborne SARs 

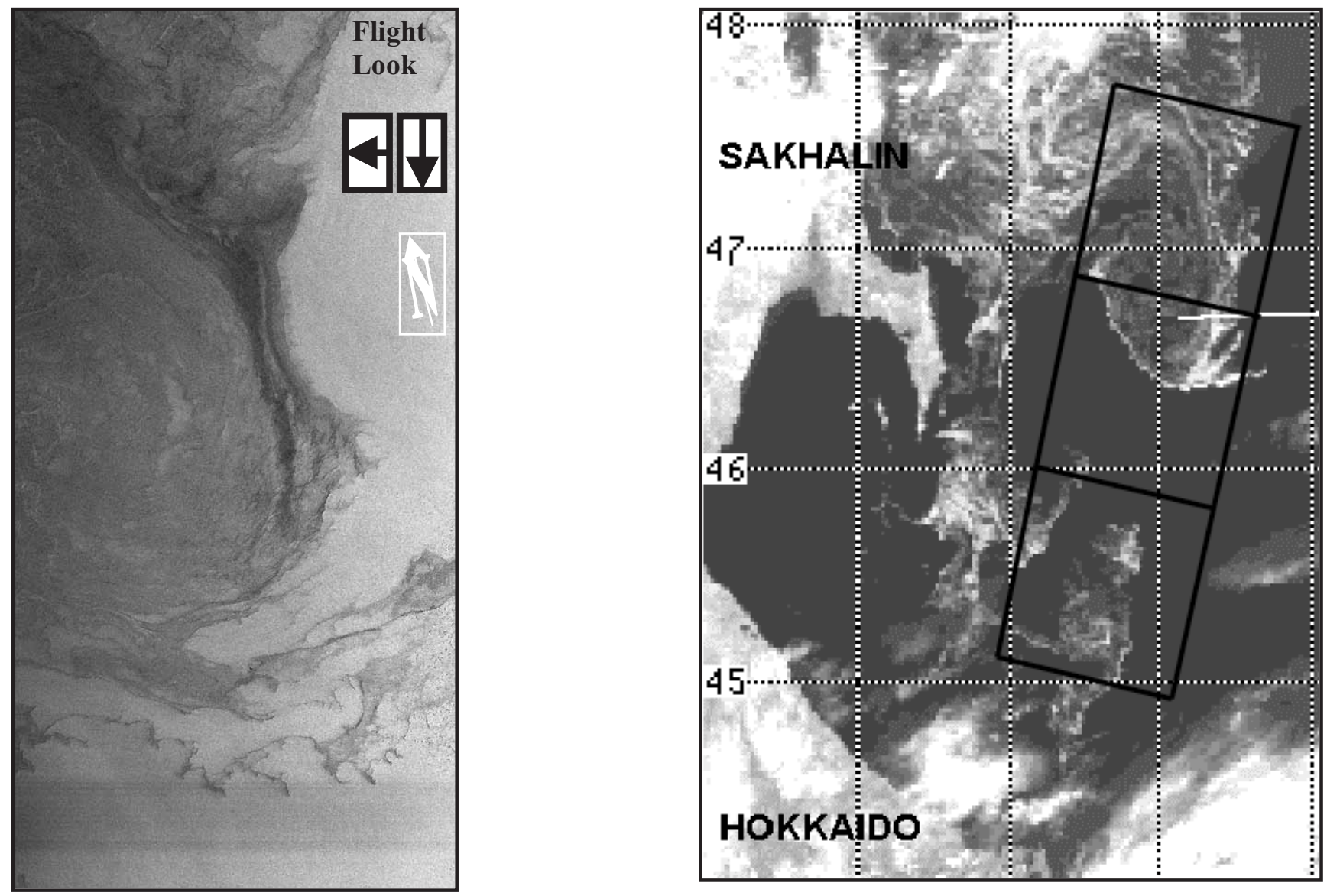

Figure 14. Anticyclonic eddy in melting ice field on the ERS-1 SAR image $(100 \times 200 \mathrm{~km})$ taken on April $22 \mathrm{nd}$, 1995 at 01:11 UTC in the Sea of Okhotsk (left). The same eddy on the NOAA AVHRR image taken on April 25th, 1995 at 03:47 UTC (right); the upper and middle rectangles indicate the location of the ERS-1 SAR image (reproduced from Lobanov et al 2000).

have limitations in the sense that the observed field of short waves intensity or radar cross section depends on a number of phenomena at the ocean/atmosphere interface so that interpretation of the SAR imagery often becomes difficult. Operational measuring and monitoring of most of the phenomena associated with ocean vortex motions requires present-day spaceborne techniques. Spatial resolution of SAR of about 50-100 m, swath width of $400-500 \mathrm{~km}$ and revisit time of the same area of about several hours are required to study and understand a wide variety of oceanic eddies.

Combination of SAR, IR and color data will be a powerful method for study and monitoring of oceanic eddies. In particular, the combination of the ASAR and MERIS images from ENVISAT will offer such an opportunity. Satellite altimeter data can also be used for these purposes. Finally, it is possible to hope that the combination of remote and traditional contact methods as well as further studies will make clear a number of unknown aspects of formation and evolution of eddies in the ocean.

\section{Acknowledgements}

The authors are very grateful to Prof. Werner Alpers from Institute of Oceanography, University of Hamburg, Dr. Leonid Mitnik from Pacific Oceanological Institute, RAS, Dr. Olga Lavrova and Dr. Konstantin Litovchenko from Space Research Institute RAS, and Dr. Neil Stapleton from DERA, who kindly agreed to provide the SAR images of oceanic eddies for this paper. Some of the presented images are also displayed on the web site "ERS SAR views the tropical and subtropical ocean" (http://www.ifm.uni-hamburg.de/erssar/index.html). Part of the presented ERS-1/2 SAR images have been acquired in the framework of the ESA AO-3 projects \#215 and 451. The study has been partially supported by the Russian Foundation for Basic Research (grant 0105-64063). Authors also acknowledge valuable comments of anonymous reviewers. 


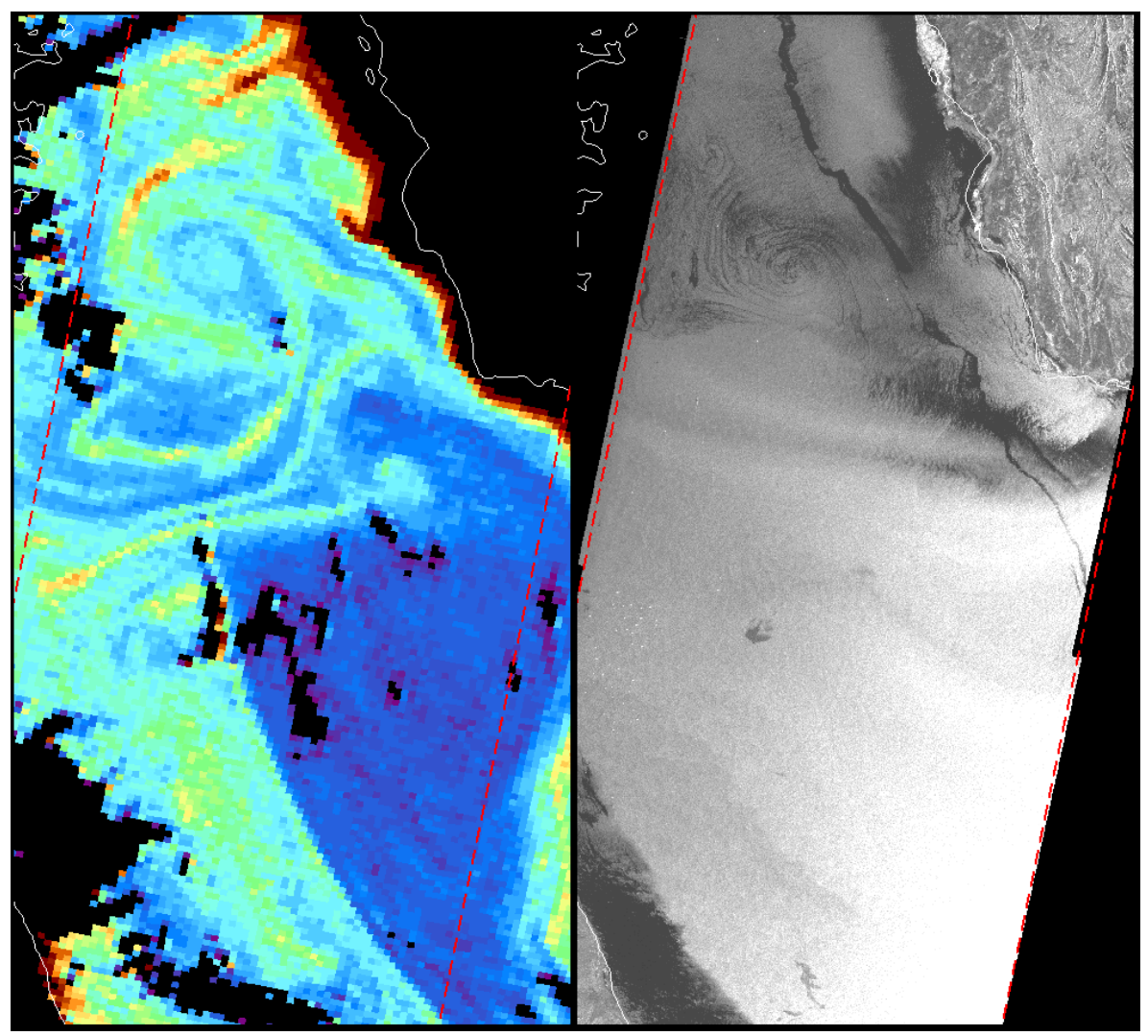

Figure 15. SeaWiFS chlorophyll image (left) and ERS-2 SAR image (right) acquired on March 8 th, 1999 in the Gulf of Oman, at 8:14 and 6:49 UTC, respectively. A spiral eddy is evidently traced by phytoplankton concentration on the SeaWiFS image and by surface films on the SAR image (reproduced from Stapleton et al 2000).

\section{References}

Alpers W and Huhnerfuss H 1989 The damping of ocean waves by surface films: a new look at an old problem; $J$. Geophys. Res. 94 pp. 6251-6265

Brown R A 1980 Longitudinal instabilities and secondary flows in the planetary boundary layer: A Review; Rev. of Geophysics and Space Physics, 18 (3) pp. 683-697

Cheney R E 1981 A search for cold water ring. In: Spaceborne synthetic aperture radar for oceanography. (The Johns Hopkins University Press) pp. 161-170

Eldevik T and Dysthe K B 2000 Short frontal waves: can frontal instabilities generate small scale spiral eddies? In: Oceanic fronts and related phenomena (Konstantin Fedorov International Memorial Symposium), International Oceanographic Commission Workshop Report No 159, Moscow, GEOS, pp. 112-117

Fedorov K N 1986 The Physical Nature of Oceanic Fronts. (Springer Verlag), $333 \mathrm{p}$.

Fedorov K N and Ginsburg A I 1986 "Mushroom-like" currents (vortex dipole) in the ocean and in laboratory tank; Annales Geophysicae 4, B, 5. pp. 507-516

Fedorov K N and Ginsburg A I 1992 The near-surface layer of the ocean. (VSP, Utrecht, The Netherlands) $259 \mathrm{p}$.

Fu L-L and Holt B 1982 Seasat views oceans and sea ice with synthetic-aperture radar; JPL Publication 81-120, JPL California Institute of Technology, Pasadena, California, $200 \mathrm{p}$.

Gairola R M, Basu S and Pandey P C 2001 Eddy detection over southern Indian Ocean using TOPEX/Poseidon altimeter data; Marine Geodesy, 24 pp. 107-121
Ginzburg A I 1992 Nonstationary eddy motions in the ocean; Oceanology (English translation), 32, 6, pp. 689-694

Grodsky S, Kudryavtsev V and Ivanov A 2000 Quasisynchronous observations of the Gulf Stream frontal zone with Almaz-1 SAR and measurements taken on board the R/V Akademik Vernadsky; The Global Atmosphere and Ocean Systems, 7, pp. 249-272

Ivanov A Yu 1999 Oceanographic results from the ALMAZ1 mission. In: Ocean surface layer: Physical processes and remote sensing. Nizhnii Novgorod, IAP RAS. v.2, pp. 408-438 (in Russian).

Ivanov A Yu and Litovchenko K T 1998 Ocean phenomena seen from ALMAZ-1. In: Remote Sensing of the Pacific Ocean by satellites (ed) R A Brown. (Australia: Earth, Ocean \& Space Publishing), pp. 93-110

Johannessen J A, Digranes G, Espedal H, Johannessen O M, Samuel P, Browne D and Vachon P 1995 SAR Ocean Feature Catalogue. Noordwijk: European Space Agency Publication Division (ESA SP-1174), 106 p.

Johannessen J A, Shuchman R A, Digranes G, Lyzenga D R, Waskerman C, Johannessen $\mathrm{O} \mathrm{M}$ and Vachon $\mathrm{P}$ W 1996 Coastal ocean fronts and eddies imaged with ERS1 synthetic aperture radar; J. Geophys. Res. 101 pp. 6651-6667

Johannessen J A, Shuchman R A, Johannessen O M, Davidson K L and Lyzenga D 1991 Synthetic aperture radar imaging of upper ocean circulation and wind fronts; $J$. Geophys. Res. 96 pp. 10,411-10,422

Johannessen O M, Johannessen J A, Svendsen E, Shuchman R A, Campbell W J and Josberger E G 1987 Ice 
edge eddies in the Fram Strait marginal ice zone; Science 236 p. 427

Kamenkovich V M, Koshlyakov M N and Monin A S 1987 Synoptic eddies in the ocean (Leningrad, Gidrometeoizdat) $511 \mathrm{p}$.

Lavrova O Yu and Sabinin K D 2000 SAR observation of dynamic processes in the Bering Strait. Paper presented at the PORSEC 2000 Conference, Goa, India, 5-8 December 2000

Lichy D E, Mattie M G and Mancicni L J 1981 Tracking of a warm water ring. In: Spaceborne synthetic aperture radar for oceanography (The Johns Hopkins University Press) pp. $171-184$

Lobanov V, Mitnik L and Dubina V 2000 Visualization of mesoscale and small-scale water dynamics in the Okhotsk Sea using satellite images. Paper presented at the 15th Int. Symp. on the Okhotsk Sea and Sea Ice, 6-9 February 2000, Mombetsu, Hokkaido, Japan

Lyzenga D R 1991 Interaction of short surface and electromagnetic waves with ocean fronts; J. Geophys. Res., 96 pp. $10,765-10,772$

Mayers S D and Basu S 1999 Eddies in the eastern Gulf of Alaska from TOPEX/Poseidon altimetry; J. Geophys. Res. 104 pp. 13,333-13,343

Munk W, Armi L, Fisher K and Zachariasen F 2000 Spirals on the sea. Proc. Royal Society. London A, 456, pp. $1217-1280$
Oceanography from the Space Shuttle, 1989. A Joint Project of the University Corporation for Atmospheric Research and the Office of Naval Research, US Navy, $200 \mathrm{p}$.

Pattiaratchi C, James A and Collins M 1987 Island wakes and headland eddies: A comparison between remotely sensed data and laboratory experiments; J. Geophys. Res. 92 (C1) pp. 783-794

Scott J C 1986 Surface films in oceanography. ONRL Workshop Report C-11-86. Off. Nav. Res., London, pp. 19-34

Scully-Power P 1986 Navy oceanographer Shuttle observations. STS 41-G Mission Report. Naval Underwater Systems Center, NUSC Technical Document 7611.

Stapleton N, Aicken W, Dovey P and Small J 2000 A multisensor approach to monitor oceanography in the Gulf of Oman and northern Arabian Sea; Proceedings of the ERS-ENVISAT Symposium, Gothenburg, Sweden, 16-20 October 2000 (ESA SP-461/CD-ROM).

Vesecky J F and Stewart R H 1982 The observation of ocean surface phenomena using imagery from the SEASAT synthetic aperture radar: An assessment; J. Geophys. Res. 87 (C5), pp. 3397-3430

Vyas N K and Andharia H I 1987 Determination of the velocity of the ocean gyres through synthetic aperture radar; Int. J. of Remote Sensing, 8 (2), pp. 243-249 